\title{
Platelet-Rich Plasma: A Review of Biology and Applications in Plastic Surgery
}

\author{
Eppley, Barry L. M.D., D.M.D.; Pietrzak, William S. Ph.D.; Blanton, Matthew \\ M.D.(Plastic Reconstructive Surgery, Volume 118(6), November 2006, pp 147e-15
}

\begin{abstract}
Learning Objectives: After studying this article, the reader should be able to: 1 . Define the role of platelets in hemostasis and wound healing. 2. Describe the technologies for platelet concentration and application. 3. Characterize the platelet concentration and growth factor components of platelet-rich plasma. 4. List the potential applications of platelet-rich plasma in plastic surgery and how it may be applied intraoperatively. 5. Discuss the limitations of the use of platelet-rich plasma and its potential complications.
\end{abstract}

Summary: Healing of hard and soft tissue is mediated by a complex array of intracellular and extracellular events that are regulated by signaling proteins, a process that is, at present, incompletely understood. What is certain, however, is that platelets play a prominent if not deciding role. Controlled animal studies of soft and hard tissues have suggested that the application of autogenous platelet-rich plasma can enhance wound healing. The clinical use of platelet-rich plasma for a wide variety of applications has been reported; however, many reports are anecdotal and few include controls to definitively determine the role of platelet-rich plasma. The authors describe platelet biology and its role in wound healing; the preparation, characterization, and use of platelet-rich plasma; and those applications in plastic surgery for which it may be useful.

Healing of hard and soft tissue is mediated by a complex array of intracellular and extracellular events that are regulated by signaling proteins, a process that is, at present, incompletely understood.1-5 What is certain, however, is that platelets play a prominent if not deciding role.3,6 Platelet activation in response to tissue damage and vascular exposure results in the formation of a platelet plug and blood clot to provide hemostasis and the secretion of biologically active proteins. These proteins, in turn, set the stage for tissue healing, which includes cellular chemotaxis, proliferation, and differentiation; removal of tissue debris; angiogenesis; and the laying down of extracellular matrix and regeneration of the appropriate type of tissue. 2-4,6 In vitro, there is a dose-response relationship between platelet concentration and the proliferation of human adult mesenchymal stem cells, the proliferation of fibroblasts, and the production of type I collagen.7,8 This suggests that the application of autogenous platelet-rich plasma can enhance wound healing, as has been demonstrated in controlled animal studies for both soft and hard tissues. 9,10

The clinical use of platelet-rich plasma for a wide variety of applications has been reported, most prevalently in the problematic wound, maxillofacial, and spine literature. 2,11-28 Collectively, these studies provide strong evidence to support the clinical use of platelet-rich plasma; however, many reports are anecdotal and few include controls to definitively determine the role of platelet-rich plasma. In addition, there is little consensus regarding platelet-rich plasma production and characterization, which 
can impede the establishment of standards that are necessary to integrate the vast literature in basic and clinical science on the subject. 29-33 The objectives of this review are to describe platelet biology and its role in wound healing; the preparation, characterization, and use of platelet-rich plasma; and those applications in plastic surgery for which it may be useful.

\section{PLATELET ORIGIN, MORPHOLOGY, AND DISTRIBUTION}

Platelets are cytoplasmic fragments of megakaryocytes (a type of white blood cell), are formed in the marrow, and are round or oval in shape, approximately $2 \mu \mathrm{m}$ in diameter.34-36 They have a trilaminar cell membrane with a glycoprotein receptor surface overlying and partially interspersed with and penetrating a bilayer of phospholipids and cholesterol.26 Platelets lack nuclei but contain organelles and structures such as mitochondria, microtubules, and granules ([alpha], [delta], and [lambda]).11,26,36,37 There are approximately 50 to 80 [alpha]-granules per platelet, each bound by a unit membrane and formed during megakaryocyte maturation.38 The [alpha]-granules are approximately 200 to $500 \mathrm{~nm}$ in diameter and contain over 30 bioactive proteins, many of which have a fundamental role in hemostasis and/or tissue healing.3,38 The platelet cytoplasm contains an open, canalicular system that increases the effective surface area for intake of stimulatory agonists and the discharge of effector secretions.

The submembrane region contains microfilaments of actin and myosin that mediate morphologic alterations.26 These cells possess a tricarboxylic acid cycle and use glucose by means of the glycolytic and hexose monophosphate shunt pathways.36 Their function is closely linked to their metabolic activity.

Platelets reside intravascularly and are concentrated in the spleen.36 The normal concentration of platelets in blood is approximately 140,000 to 400,000 platelets $/ \mathrm{mm}^{3}$. These remain in the circulation for an average of approximately 10 days before removal by macrophages of the reticuloendothelial system. 26,36

\section{PLATELET FUNCTION IN HEMOSTASIS AND WOUND HEALING}

Functionally, platelets are involved with both hemostasis and the initiation of wound healing. This, however, is a somewhat arbitrary division because hemostasis can be considered to be the first stage of healing.39

\section{PLATELET ROLE IN HEMOSTASIS}

After tissue injury, platelets become exposed to damaged blood vessels, which places them in direct contact with collagen, the basement membranes of capillaries, and subendothelial microfibrils. 36 This interaction causes the platelets to aggregate at the site and change from a rounded shape to one that includes large, sticky protuberances, or pseudopodia.26,37 This process is called activation. During activation, the [alpha]-granules fuse with the platelet plasma membrane and release their protein contents to the surroundings, a topic that is described in more detail below as related to the role of platelets in tissue healing. Other factors that mediate activation include adenosine diphosphate, which is released by activated platelets, and thrombin and adrenalin.36,37 For small vascular defects, this platelet plug may be sufficient to stop blood loss; however, if the defect is large, a blood clot may be required.

Blood clotting is initiated by one of two pathways, namely, the intrinsic and extrinsic pathways.36 The intrinsic pathway is initiated by damage or alteration to the blood, itself, whereas the extrinsic pathway is 
initiated by contact of blood with factors that are extraneous to the blood (e.g., damaged tissue). Both pathways involve a cascaded reaction sequence whereby inactive factors become activated which, in turn, catalyze the formation of other products from precursors that go on to catalyze subsequent reactions, leading to the formation of a formal clot. Although both pathways begin differently, they converge and share many of the latter steps in the reaction series, as shown in Figure 1. As is evident, calcium ion is required for the reaction to proceed to completion. Platelets participate at multiple levels in the reaction sequence that generates fibrin threads, and are part of the final clot composition, which consists of a fibrin mesh, with the activated platelet aggregate and red and white blood cells interposed within. Within 20 minutes to 1 hour after clot formation, the clot retracts by means of contraction of the platelet actin-myosin fibers.26,34 Such retraction helps to further close the vessel. It is during this time that the platelet releasate, which includes the contents of the [alpha]-granules, is expressed. Local vasoconstriction in response to the release of thromboxane and serotonin from the platelet aggregate also aids hemostasis. 2 The ability for blood to clot must be disabled for blood to be maintained in the liquid state, ex vivo, for transfusion or processing purposes. Because free calcium ion is required for blood to clot, one effective means of preventing this is to bind the calcium ion so it is unable to participate in the reaction sequence. Citrate ion is typically added, which binds with calcium ion, forming calcium citrate, a soluble but un-ionizable substance. Typical blood preservatives include acid citrate dextrose and citrate phosphate dextrose which, in addition to citrate, contain other substances to maintain cellular viability.31,35 


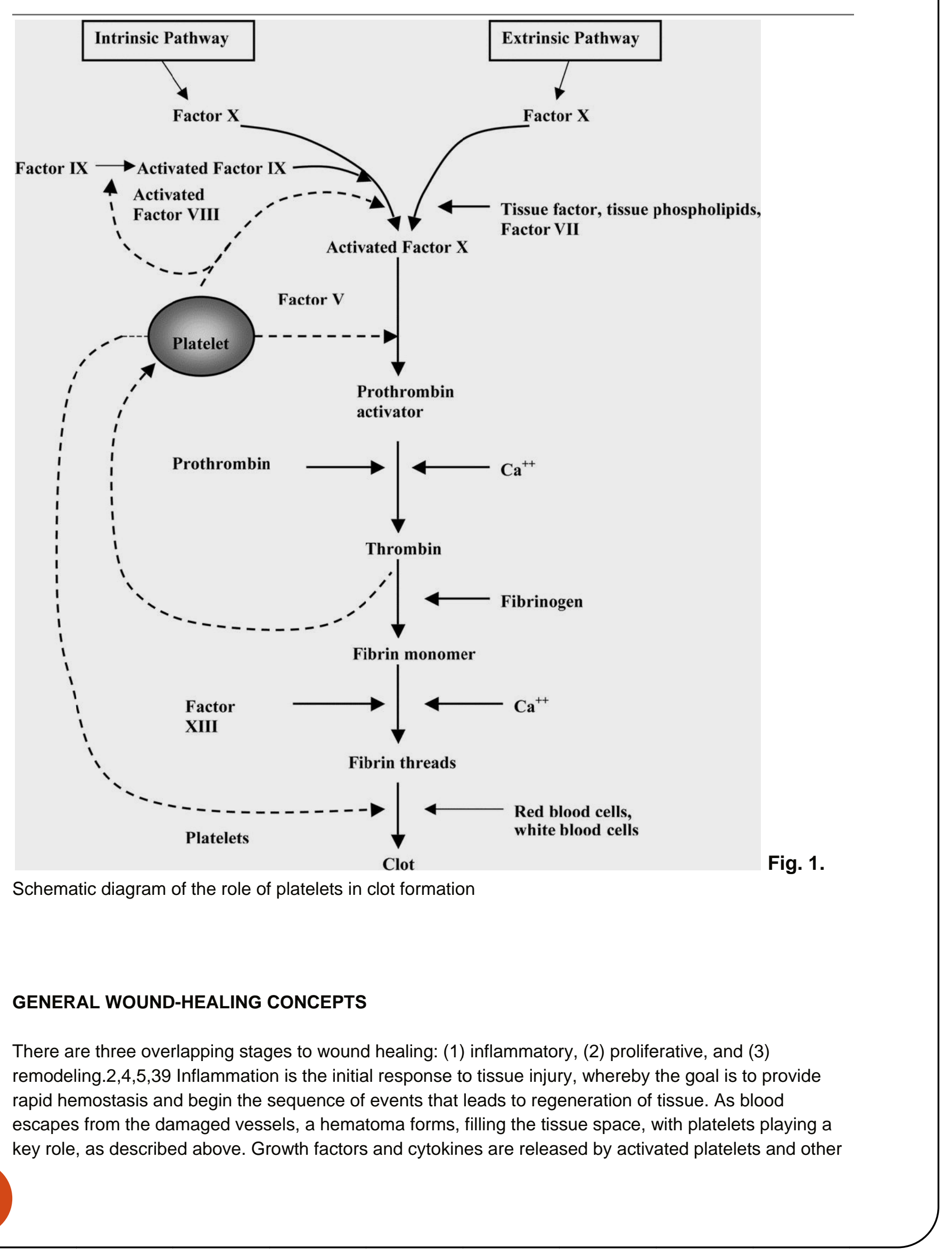


cells, resulting in cell migration, proliferation, differentiation, and matrix synthesis.4,5 The fibrin mesh of the hematoma functions as a provisional matrix to maintain the regenerative space and provide a scaffold for cell migration and proliferation.5,16

The first inflammatory cells to invade the wound site are neutrophils, which provide rapid protection against infection and removal of tissue debris, having lifetimes measured in hours and days.2,4-6,39 Next, there is an influx of monocytes and T lymphocytes.

The monocytes differentiate to macrophages and become the predominant cell type. Macrophages have lifetimes measured in days to months and assist the neutrophils in their function and in secreting factors that direct succeeding events.2,4-6 The role of the T lymphocytes in successful wound repair is presently unclear.39 Mesenchymal stem cells migrate into the region, providing the uncommitted cell line that will be responsible for formation of bone, cartilage, fibrous tissue, blood vessels, and other tissues. 4 Fibroblasts migrate into the region and begin to proliferate, producing extracellular matrix.4,40 Blood vessel endothelial cells near the injury proliferate and form new capillaries that extend into the injured site. This begins the process of angiogenesis.2,4 Near the end of the inflammatory phase, granulation tissue, with a pink, soft, granular appearance, forms. This is a transient, well-vascularized tissue devoid of nerves but rich in fibroblasts, capillaries, and chronic inflammatory cells that provides a metabolically rich environment to aid repair.5,41

During the second, or proliferative, phase of wound healing, the damaged, necrotic tissue is removed and replaced by living tissue that is specific to the local tissue environment (e.g., bone, cartilage, fibrous tissue). The mesenchymal stem cells differentiate into osteoblasts, fibroblasts, chondrocytes, and other cell types as required to generate the appropriate type of tissue.4 Local factors, including the growth factor and cytokine profile, hormones, nutrients, $\mathrm{pH}$, oxygen tension, and the electrical and mechanical environment, mediate the appropriate differentiation. 4

The third and final phase of wound healing is remodeling. During this phase, the newly generated tissue reshapes and reorganizes to more closely resemble the original tissue. Changes that occur include a reduction in cell density and vascularity, removal of excess repair matrix, and orientation of the collagen fibers of the repair matrix along lines of stress to maximize strength.2,4 Bone remodeling is generally described by Wolff's law.4,42 This final stage of healing can require years for completion.2,4

Scar tissue differs from normal tissue in that it is regenerated tissue that consists primarily of fibroblasts and matrix and may restore integrity but not form and function.4 Soft tissue and skin heals by scar formation.4,43 The healed tissue, however, may consist of some components of the original tissue that have reformed within the scar. Bone is unique in that it typically heals without scar (i.e., the healed tissue cannot be distinguished from uninjured bone). 4 Tissue, patient, and treatment variables affect the rate and quality of the healing response.4

\section{PLATELET ROLE IN WOUND HEALING}

Numerous proteins are contained within the [alpha]-granules of platelets that strongly influence wound healing, including platelet-derived growth factor (PDGF) (including [alpha][alpha], [beta][beta], and [alpha][beta] isomers), transforming growth factor (TGF)-[beta] (including [beta]1 and [beta]2 isomers), platelet factor 4 (PF4), interleukin (IL)-1, platelet-derived angiogenesis factor (PDAF), vascular endothelial growth factor (VEGF), epidermal growth factor (EGF), platelet-derived endothelial growth factor (PDEGF), 
epithelial cell growth factor (ECGF), insulin-like growth factor (IGF), osteocalcin, osteonectin, fibrinogen, vitronectin, fibronectin, and thrombospondin (TSP)-1.2,6,16,23,26,34,38,44 Collectively, these proteins are members of the families of growth factors, cytokines, and chemokines which, for the purpose of this review, are broadly referred to as secretory proteins.

Activation, also known as degranulation, causes the [alpha]-granules to fuse to the platelet cell membrane, where at least some of the secretory proteins (e.g., PDGF and TGF-[beta]) are transformed to a bioactive state by the addition of histones and carbohydrate side chains.6,11,38 The active proteins are then secreted, allowing them to bind to the transmembrane receptors of target cells (e.g., mesenchymal stem cells, osteoblasts, fibroblasts, endothelial cells, and epidermal cells). Once bound to the transmembrane receptors, intracellular signal proteins are activated, which results in the expression of a gene sequence that directs cellular proliferation, matrix formation, osteoid production, collagen synthesis, and so forth. 6

Platelets begin to actively secrete these proteins within 10 minutes after clotting, with more than 95 percent of the presynthesized growth factors secreted within 1 hour. 6 After this initial burst of protein release, the platelets synthesize and secrete additional proteins for the balance of their life (5 to 10 days).6,16,33 As the direct platelet influence begins to subside, macrophages, which arrive by means of vascular ingrowth stimulated by the platelets, assume responsibility for wound-healing regulation by secreting their own factors. Thus, the platelets at the repair site ultimately set the pace for wound repair.6,35

The many proteins secreted by the activated platelets influence many aspects of wound healing, and Anitua et al.3 have provided a recent, detailed review. For example, PDGF is chemotactic for macrophages whereas, collectively, PDGF, TGF-[beta], and IGF assist in chemotaxis and mitogenesis of stem cells and osteoblasts, angiogenesis for capillary ingrowth, bone matrix formation, and collagen synthesis.3,16,24 TGF-[beta] and PDGF also assist in bone mineralization.10 As a group, the adhesive proteins fibrinogen, fibronectin, vitronectin, and TSP-1 participate in thrombus formation, and some appear to have some mitogenic characteristics as well.3,45,46 Some of the secretory proteins released from platelets are absent in chronic, nonhealing wounds, providing further evidence of their role in wound healing.26 Although it is generally believed that platelets do not contain bone morphogenetic proteins (BMPs),6,35 Sipe et al.47 recently identified both BMP-2 and BMP-4 within platelet lysate, suggesting the possibility that this might contribute to the platelet role in bone formation and repair. A schematic diagram of the role of platelets in wound healing is shown in Figure 2.

Although platelets are central to normal wound healing, healing can occur in their absence. For instance, animals rendered thrombocytopenic, although displaying altered wound-healing characteristics that may be site-dependent, may go on to heal, perhaps through the involvement of compensatory mechanisms.39 


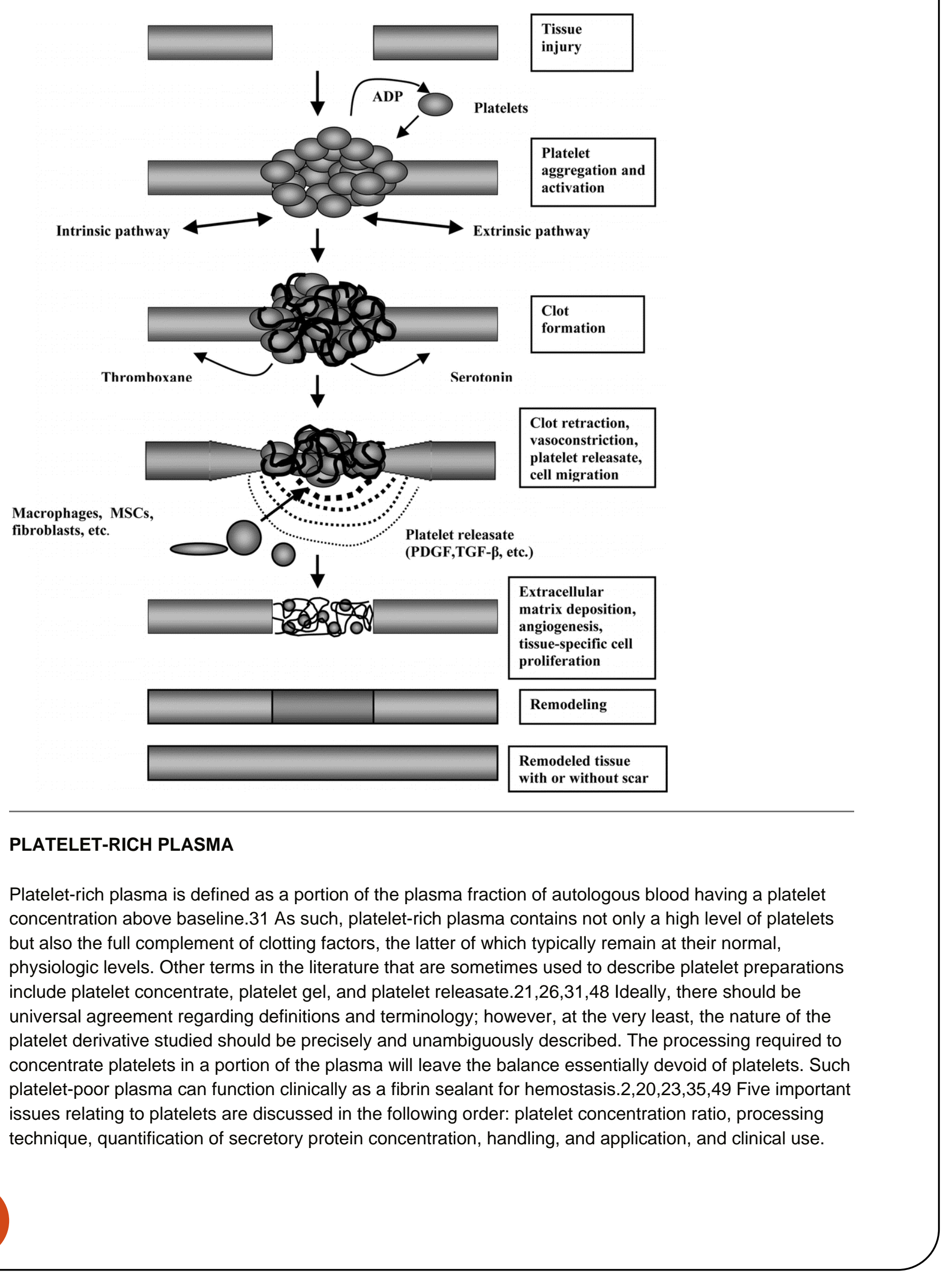




\section{Platelet Concentration Ratio}

To a first approximation, the amount of hematoma that forms in response to trauma is proportional to the degree of tissue injury. In this way, delivery of platelet-rich plasma can be thought of as responding with hematoma in excess of that which would have been physiologically produced. It is likely that the effect of platelet-rich plasma on wound healing is a function of many variables, including the platelet concentration, platelet-rich plasma volume delivered, the extent and type of injury, and the overall medical condition of the patient. The large number of variables and their potential for interaction is probably the reason that there is no single recommendation for the degree of increase of platelets in platelet-rich plasma over baseline.

Some investigators have suggested that platelet-rich plasma should achieve a 3 to 5 -fold increase in platelet concentration over baseline, $11,30,48$ although the dependence of clinical benefit on platelet concentration versus total number of platelets delivered may need to await further investigation. 32 Platelet concentration ratios of less than 2-fold to 8.5 -fold have been reported.6,11,22,29,30,48,50 Weibrich et al.44 suggest that different individuals may require different platelet concentration ratios to achieve comparable biological effect.

\section{Processing Technique}

During surgery, platelets will collect at the surgical site to initiate clotting and healing, somewhat reducing the whole blood platelet count.31 As such, blood should be drawn before surgery begins because the surgery itself will lead to platelet activation that may interfere with preparation.20,23

When anticoagulated blood is centrifuged, three layers form as a function of density: the bottom layer consisting of red blood cells (specific gravity, 1.09), the middle layer consisting of platelets and white blood cells (buffy coat; specific gravity, 1.06), and the top plasma layer (specific gravity, 1.03).26 Centrifugation forms the basis of current methods for producing platelet-rich plasma, with the yield approximately 10 percent, by volume, of whole blood drawn. Platelet fragmentation during processing should be avoided. Because it is the process of activation that results in the completion of the tertiary structure of some of the secretory proteins, such fragmentation during processing could result in the release of high levels of proteins, with compromised bioactivity. 48 The integrity of the platelet membrane can be preserved by use of acid citrate dextrose type $A$ anticoagulant and low gravity forces during centrifugation. 31,48

In addition, platelet activation occurring during processing should be kept to a minimum. Although bioactive secretory proteins would be produced, they might be lost and not transferred to the surgical bed when the clot is implanted, although the magnitude of this may be a function of the mode of delivery.29 Pselectin is a protein contained in the inner face of the [alpha]-granule membrane.38 On platelet activation, the [alpha]-granule membrane fuses with the platelet membrane and P-selectin becomes expressed on the platelet surface, where it can be measured and the amount of platelet activation determined.38,48 Thus, measurement of $\mathrm{P}$-selectin provides valuable information regarding the platelet-rich plasma preparation. 29,30

Although it is possible to use a standard laboratory centrifuge to produce platelet-rich plasma, the process is labor intensive, generally requiring two spins and multiple transfers; consequently, sterility may be 
difficult to maintain.31,48,51 Furthermore, such techniques may not reliably maximize the platelet concentration or the levels of key secretory proteins. 6

Standard cell separators and salvage devices can be used to produce platelet-rich plasma. These devices operate on a unit of blood and typically use continuous-flow centrifuge bowl or continuous-flow disk separation technology and both a hard (fast) and a soft (slow) spin, yielding platelet concentrations from two to four times baseline.30,52,53 Such devices include the CATS (Fresenius, Wilmington, Del.), Sequestra (Medtronic, Minneapolis, Minn.), Haemonetics Cell Saver 5 (Haemonetics Corp., Braintree, Mass.), and others.30,32,52

Many surgical procedures require use of relatively small volumes of platelet-rich plasma.20,23 Some of these procedures may be performed in an office setting, making draw of a full unit of blood undesirable and legally precluding the reintroduction of the unused portion of the blood to the patient.31

Consequently, small, compact office systems have been developed that produce approximately $6 \mathrm{ml}$ of platelet-rich plasma from 45 to $60 \mathrm{ml}$ of blood, obviating the need for reinfusion.6,20,31,54,55 There are many such systems, including the GPS (Biomet, Warsaw, Ind.), the PCCS (Implant Innovations, Inc., Palm Beach Gardens, Fla.), the Symphony II (DePuy, Warsaw, Ind.), the SmartPReP (Harvest Technologies Corp., Norwell, Mass.), and the Magellan (Medtronic, Minneapolis,

Minn.).6,29,30,32,35,52,54 Although all operate on a small volume of drawn blood (45 to $60 \mathrm{ml}$ ) and on the principle of centrifugation, these systems differ widely in their ability to collect and concentrate platelets, with approximately 30 to 85 percent of the available platelets collected and from a less than 2fold to an approximately 8 -fold increase in the platelet concentration over baseline.6,29,30,52

In general, most systems, whether large or small volume, do not concentrate the plasma proteins of the coagulation cascade.30,32,56 The concentration of plasma protein levels above baseline can be achieved though secondary ultrafiltration, as is done with the UltraConcentrator (Interpore Cross, Irvine, Calif.), and the Access System (Interpore Cross), in which the buffy coat collected from a centrifugation stage is passed through hollow fibers with an effective pore size of $30 \mathrm{kDa}$. With this system, up to twothirds of the aqueous phase is removed by filtration; thus, the concentrations of the retained plasma proteins and formed elements are correspondingly increased.56,57

\section{Quantification of Secretory Protein Concentration}

The regenerative potential of platelet-rich plasma depends, to large extent, on the levels of secretory proteins that are released on platelet activation.29,44 These protein levels will depend on several factors, including (1) the concentrations of these proteins contained in the platelets (a patient variable); (2) the processing technique, which will influence platelet concentration and whether platelets are activated or fragmented during preparation; and (3) the completeness of platelet activation before measurement.29,31,44,58

The secretory proteins must first be released from the platelets before they can be measured. Release can be accomplished through platelet activation or through physical disruption of the platelet/[alpha]granule structure. The most common method of platelet activation is to add calcium chloride and thrombin to the platelet-rich plasma.23,29,35,48 The thrombin directly activates platelets, and the calcium ion replenishes that which was bound by the acid citrate dextrose type $A$ anticoagulant. Although this method is often used to activate platelet-rich plasma clinically, the activation that occurs during clot formation 
does not necessarily lead to complete release.33 Another activation method uses adenosine diphosphate, which acts directly on the platelets.59,60

Secretory protein levels are commonly expressed in concentration units (e.g., measured amount per milliliter of releasate or per 100,000 platelets). Weibrich et al.,44 using a freeze/thaw cycle to release proteins, measured the levels of PDGF-[alpha][beta], PDGF-[beta][beta], TGF-1, TGF-[beta]2, and IGF-1 in specimens of platelet-rich plasma derived from 115 patients. Minimum and maximum values for each typically spanned one to two orders of magnitude, with means \pm SD of $117.5 \pm 63.4 \mathrm{ng} / \mathrm{ml}, 9.9 \pm 7.5$ $\mathrm{ng} / \mathrm{ml}, 169.4 \pm 84.5 \mathrm{ng} / \mathrm{ml}, 0.4 \pm 0.3 \mathrm{ng} / \mathrm{ml}$, and $84.2 \pm 23.6 \mathrm{ng} / \mathrm{ml}$, respectively. They found statistical correlations between the concentrations of the following pairs of growth factors: PDGF[alpha][beta]/PDGF-[beta][beta], PDGF-[alpha][beta]/TGF-[beta]1, and PDGF-[beta][beta]/TGF-[beta]1. There was little or no correlation between the levels of these individual proteins and donor age and gender attributes. Eppley et al.29 used thrombin/calcium chloride to activate platelets and release proteins from platelet-rich plasma derived from 10 healthy volunteers. Secretory protein levels measured were $17 \pm 8 \mathrm{ng} / \mathrm{ml}$ (PDGF-[beta][beta]), $120 \pm 42 \mathrm{ng} / \mathrm{ml}$ (TGF-[beta]1), $955 \pm 1030 \mathrm{ng} / \mathrm{ml}$ (VEGF), $129 \pm$ $61 \mathrm{ng} / \mathrm{ml}$ (EGF), and $72 \pm 25 \mathrm{ng} / \mathrm{ml}$ (IGF-1). Zimmermann et al.33 used various methods to initiate platelet release and measured levels of PDGF-[alpha][beta], PDGF-[beta][beta], and TGF-[beta]1 in platelet-rich plasma preparations both rich and deficient in white blood cells, expressing levels both on a per-milliliter and a per-100,000 platelet basis. For a given protein, there was typically a 3- to 4-fold range in measured level versus release method, and the authors concluded that the release of each growth factor by a given sample preparation method must be investigated and interpreted separately.

All else being equal, one would expect that the concentration of released secretory proteins would be linearly proportional to the platelet concentration ratio. Although such a relationship between some secretory proteins (i.e., PDGF-[alpha][beta], TGF-[beta], VEGF, and EGF) and platelet count has been reported,59 an additional study by the same principal author confirmed this relationship only for PDGF, TGF-[beta], and EGF, but not for VEGF and IGF.60 Although a general trend of increasing protein content and platelet count for a variety of secretory proteins (PDGF-[alpha][beta], PDGF-[beta][beta], TGF-1, TGF-[beta]2, VEGF, EGF, and IGF-1) was demonstrated, Eppley et al.29 and Weibrich et al.44 found little value in using platelet concentration ratio to predict resultant platelet-rich plasma secretory protein levels. Eppley et al.,29 using thrombin/calcium chloride to activate the platelets, found variable concentration ratios for several secretory proteins, all lower than the platelet concentration ratio. Incomplete platelet activation and variable binding of the expressed proteins to the clot, which would not have been measured in the platelet-rich plasma supernatant, could be a partial explanation.

\section{Handling and Application of Platelet-Rich Plasma}

After preparation, platelet-rich plasma is stable, in the anticoagulated state, for 8 hours, or longer, permitting the blood to be drawn before surgery and used, as needed, during lengthy operations.6,31,61 The platelet-rich plasma must be activated for the platelets to release their [alpha]-granule contents, with the clot that forms providing a vehicle to contain the secreted proteins and maintain their presence at the wound site. This is most commonly performed by adding a solution of 1000 units of topical bovine thrombin per milliliter of $10 \%$ calcium chloride to the platelet-rich plasma.2,20,22,29 Marx et al.22 described a technique in which $6 \mathrm{ml}$ of platelet-rich plasma, $1 \mathrm{ml}$ of the calcium chloride/thrombin mix, and $1 \mathrm{ml}$ of air (to act as a mixing bubble) is introduced into a 10-ml syringe. The syringe is agitated for 6 to 10 seconds to initiate clotting, and then the clot delivered. Alternatively, Man et al.20 described another technique for delivering the activated platelet-rich plasma. The platelet-rich plasma and calcium 
chloride/thrombin solution are mixed in a 10:1 (volume/volume) ratio by use of a dual-syringe mixing system. The platelet-rich plasma is drawn into a $10-\mathrm{ml}$ syringe and the activating solution is drawn into a 1-ml syringe. Both syringe plungers are connected to move together with both output ports connected to a dual-spray applicator tip that allows both solutions to be mixed as they are applied to the wound. Plateletpoor plasma can be delivered similarly to function as a fibrin glue or hemostatic agent.20,23 Because the [alpha]-granules quickly release their contents on activation, Marx 6 states that the clotted platelet-rich plasma should be used within 10 minutes of clot initiation.

This is not an issue with the dual-syringe spray delivery, as the platelet-rich plasma is delivered to the wound site immediately after activation. In the case of other mixing techniques, it is important to transfer the clot to the surgical site before clot retraction; otherwise, the transferred clot may be deficient in the secretary proteins that were expressed.

In the early to mid 1990s, there were a few reports of the development of antibovine antibodies (antibovine factor $\mathrm{V}$ ) that cross-reacted with human clotting factors in response to use of the bovine product to provide hemostasis to open, bleeding vessels.62-64 Although bovine thrombin is often used (along with calcium chloride) for clinical platelet activation, there is little evidence that such cross-reaction occurs for this application. This may be because (1) current processing methods remove much more bovine factor $V$ contamination and (2) its use in platelet-rich plasma gel precludes its exposure to the systemic circulation, possibly explaining why platelet-rich plasma has not produced postsurgical bleeding or shown elevation in postoperative prothrombin time or the development of detectable antibovine antibodies.10

\section{Clinical Use}

Proponents of platelet-rich plasma technology suggest that benefits include an increase in hard- and softtissue wound healing and a decrease in postoperative infection, pain, and blood loss.34 There have been numerous publications on the use of platelet-rich plasma for several clinical applications, including periodontal and oral surgery,12,14,16,18,22-25,27 maxillofacial surgery,27 aesthetic plastic surgery,2,20,26 spinal fusion,13,17,19 heart bypass surgery,15 and treatment of chronic skin and softtissue ulcers.21,65 The details of the quantity of platelet-rich plasma used and the methods of application are procedure-specific. Although the vast majority of these studies have yielded excellent outcomes, most are only limited case studies or series. As such, wound-healing enhancement by platelet-rich plasma remains largely anecdotal. There exists, however, a small collection of clinical studies with prospective or retrospective controls that have demonstrated a significant enhancement of hard- and soft-tissue healing with the use of platelet-rich plasma.11,12,15,17,21

In plastic surgery, the use of autologous blood-derived products has been largely limited to fibrin glues, primarily used to obtain hemostasis and adherence of skin flaps. The first report was in 1990 regarding a diverse use of fibrin glue (Tisseel) for multiple aesthetic facial applications (23 patients) applied on the undersurface of flaps.66 Application for a "minimal suture blepharoplasty" in 1992 with closure of incisions with autologous fibrin glue reported lower complications with milia formation than standard suture techniques. 67 A study of 20 patients by Man et al. 20 demonstrated that the use of autologous fibrin glue and platelet gel in cosmetic surgical procedures involving the creation of flaps, such as in face and neck lifts and breast reductions and augmentations, resulted in numerous advantages. These included the elimination of the need for drains, a reduction in postoperative pain and swelling, and improved wound healing. In another skin flap study, a clinical series of eight patients were unilaterally treated with 
autologous platelet-rich plasma mixed with thrombin and calcium chloride to form an autologous platelet gel to determine the effects on postoperative recovery from deep-plane rhytidectomy.68 Staged postoperative facial photographs were graded in a blinded fashion for postoperative ecchymosis and edema. Although no statistically significant differences were identified in the data, trends suggested that treatment with autologous platelet gel was better at preventing or improving ecchymosis rather than edema, and was chiefly demonstrable in the early phases of recovery. In a larger face-lift case series, a single postoperative hematoma among a cohort of 100 consecutive patients undergoing face lifting treated with bilateral autologous platelet gel occurred, an outcome reported as a significant reduction in postoperative complication incidence by the authors. No drains or postoperative dressings were used in the fibrin glue-treated group, which patients found most favorable.69 Similarly, Oliver et al. in 2001 reported on a prospective, randomized, double-blind trial of the use of fibrin sealant for face lifts in 20 patients. A significant difference in drain output occurred between control and treated sides (average, 30 $\mathrm{ml}$ for the control side and $10 \mathrm{ml}$ for the fibrin glue side). It was suggested that postoperative drains may not be needed with this technique, and that pain and bruising may likewise be reduced. 70 Favorable results were also reported by Fezza in 2002. In 24 consecutive patients, fibrin glue was used in face lifts without drains. These patients had less bruising and swelling, no incidence of hematoma, and shorter operative times compared with another group of 24 face-lift patients where glue was not used. 71 The most recent study of the efficacy of a commercial (nonautologously derived) fibrin glue on face lifts was reported by Marchac in 2005, nearly 10 years after his initial report in 1994. In a prospective study of 30 patients, there were minimal differences between glued and unglued sides in terms of drain output, bruising, swelling, or the incidence of hematomas. 72 After 17 years of clinical use, this experienced author now concludes that the theoretical benefit of fibrin in face lifts is not as great as previously hoped. In a companion experience, Jones et al. in 2004 did not find any statistical difference in hematoma rates with the use of fibrin glue compared with other prevention techniques such as dressings, drains, or the use of tumescence. 73

Results with fibrin glue fixation in forehead endoscopy were reported in 1998. In 206 endoscopic forehead procedures in 196 patients in which fibrin glue was used, good results were obtained in 86 percent of the cases, with minimal complications. Fibrin glue provided stable fixation, with the possibility of displacement in several directions, including transversal expansion.74

Numerous clinical trials have reported favorable results evaluating wounds treated with platelet releasate. Knighton et al.75 observed that 17 of 21 chronic lower extremity ulcers reepithelialized during an 8.6week (average) course of twice-daily wound treatment with platelet releasate suspended on a collagen base (platelet-derived wound-healing factor) compared with two of 13 similar wounds treated with placebo. After crossover of the placebo group, all 11 nonhealed wounds achieved 100 percent epithelialization in an average of 7.1 weeks. An earlier study by the same group, also using plateletderived wound-healing factor, demonstrated a 93 percent reepithelialization rate among 71 chronic wounds in 41 patients after daily treatments with autologous platelet concentrate. A similar clinical protocol was reported by Ganio et al. in a case series of 171 patients with 355 chronic (average, 75 weeks before presentation) lower extremity wounds. 76 Results included a 78 percent rate of limb salvage in patients for whom amputation was initially recommended after daily 12-hour treatments with plateletderived wound-healing factor for an average of 10 weeks. Marx et al.22 reported enhanced bone formation in mandibular bone grafts treated with platelet-rich plasma, an effect lasting up to 6 months postoperatively that was documented by biopsy-proven enhanced bone deposition among platelet-rich plasma-treated grafts. Table 1 summarizes these cited studies. Collectively, they provide existing evidence for the clinical use of platelet technology in the healing of both soft- and hard-tissue wounds. 


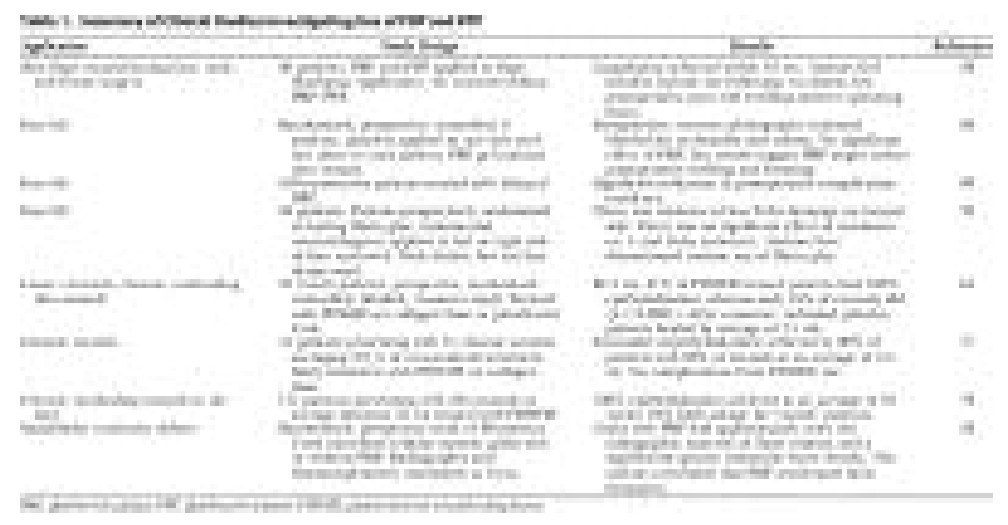

\section{Table 1. Summary of Clinical Studies Investigating Use of PRP and PPP}

\section{CONCLUSIONS}

Platelets immediately appear at the site of tissue injury in large numbers. As such, it makes evolutionary sense that platelets direct wound healing because, by design, they will be present exactly where and when needed, to create a local environment conducive to tissue regeneration. By releasing secretory proteins from their [alpha]-granules on activation, platelets set the pace of wound healing, with their effects remaining long after the clot has been cleared. The enhancement of healing by the placement of a supraphysiologic concentration of autologous platelets at the site of tissue injury is supported by basic science studies. There exist a small number of controlled, clinical studies that provide evidence that the use of autologous platelet-rich plasma does, indeed, accelerate soft- and hard-tissue healing in at least some applications. The future role of platelet-rich plasma in plastic surgery largely remains both theoretical and anecdotal at this time. Many more controlled clinical studies will be required to establish the conditions under which the application of platelet-rich plasma has merit. Currently, platelet-rich plasma use seems to offer some efficacy in certain types of acute and chronic wounds, although the timing of application is not clear. In aesthetic plastic surgery, although theoretically appealing and not harmful, the potential benefits of platelet-rich plasma may be difficult to measure in these patients with otherwise normal wound healing.

\section{DISCLOSURE}

None of the authors has a financial interest in any of the products, devices, or drugs mentioned in this article.

\section{REFERENCES}

1. Beasley, L. S., and Einhorn, T. A. Role of growth factors in fracture healing. In E. Canalis (Ed.), Skeletal Growth Factors. New York: Lippincott Williams \& Wilkins, 2000. Pp. 311-322 
2. Bhanot, S., and Alex, J. C. Current applications of platelet gels in facial plastic surgery. Facial Plast. Surg. 18: 27, 2002

3. Anitua, E., Andia, I., Ardanza, B., et al. Autologous platelets as a source of proteins for healing and tissue regeneration. Thromb. Haemost. 91: 4, 2004.

4. Buckwalter, J. A., Einhorn, T. A., Bolander, M. E., et al. Healing of musculoskeletal tissues. In C. A. Rockwood, Jr., R. W. Bucholz, and D. P. Green (Eds.), Fractures in Adults. Philadelphia: LippincottRaven, 1996. Pp. 261-304.

5. Anderson, J. M. The cellular cascades of wound healing. In J. E. Davies (Ed.), Bone Engineering. Toronto: em squared inc., 2000. Pp. 81-93

6. Marx, R. E. Platelet-rich plasma: Evidence to support its use. J. Oral Maxillofac. Surg. 62: 489, 2004.

7. Haynesworth, S. E., Kadiyala, S., Liang, L., et al. Mitogenic stimulation of human mesenchymal stem cells by platelet releasate suggest a mechanism for enhancement of bone repair by platelet concentrates (Poster no. 462). Transactions of the 48th Annual Meeting of the Orthopaedic Research Society, Dallas, Texas, February 10-13, 2002

8. Liu, Y., Kalen, A., Risto, O., et al. Fibroblast proliferation due to exposure to a platelet concentrate in vitro is pH dependent. Wound Repair Regen. 10: 336, 2002.

9. Carter, C. A., Jolly, D. G., Worden, C. E., Sr., et al. Platelet-rich plasma gel promotes differentiation and regeneration during equine wound healing. Exp. Mol. Pathol. 74: 244, 2003.

10. Fennis, J. P. M., Stoelinga, P. J. W., and Jansen, J. A. Mandibular reconstruction: A clinical and radiographic animal study on the use of autogenous scaffolds and platelet-rich plasma. J. Oral Maxillofac. Surg. 31: 281, 2002.

11. Marx, R. E. Platelet concentrate: A strategy for accelerating and improving bone regeneration. In J. E. Davies (Ed.), Bone Engineering. Toronto: University of Toronto, 2000. Pp. 447-453.

12. Anitua, E. Plasma rich in growth factors: Preliminary results of use in the preparation of future sites for implants. J. Oral Implantol. 14: 529, 1999.

13. Bose, B., and Balzarini, M. A. Bone graft gel: Autologous growth factors used with autograft bone for lumbar spine fusions. Adv. Ther. 19: 170, 2002.

14. Della Valle, A., Sammartino, G., Marenzi, G., et al. Prevention of postoperative bleeding in anticoagulated patients undergoing oral surgery: Use of platelet-rich plasma gel. J. Oral Maxillofac. Surg. 61: 1275, 2003.

15. DelRossi, A. J., Cernaianu, A. C., Vertrees, R. A., et al. Platelet-rich plasma reduces postoperative blood loss after cardiopulmonary bypass. J. Thorac. CardiovasC. Surg. 100: 281, 1990 
16. Froum, S. J., Wallace, S. S., Tarnow, D. P., et al. Effect of platelet-rich plasma on bone growth and osseointegration in human maxillary sinus grafts: Three bilateral case reports. Int. J. Periodontics Restorative Dent. 22: 45, 2002.

17. Hee, H. T., Majd, M. E., Holt, R. T., et al. Do autologous growth factors enhance transforaminal lumbar interbody fusion? Eur. Spine J. 12: 400, 2003.

18. Kassolis, J. D., Rosen, P. S., and Reynolds, M. A. Alveolar ridge and sinus augmentation utilizing platelet-rich plasma in combination with freeze-dried bone allograft: Case series. J. Periodontol. 71: 1654,2000

19. Lowery, G. L., Kulkarni, S., and Pennisi, A. E. Use of autologous growth factors in lumbar spinal fusion. Bone 25 (2 Suppl.): 47S, 1999

20. Man, D., Plosker, H., and Winland-Brown, J. E. The use of autologous platelet-rich plasma (platelet gel) and autologous platelet-poor plasma (fibrin glue) in cosmetic surgery. Plast. Reconstr. Surg. 107: 229, 2001.

21. Margolis, D. J., Kantor, J., Santanna, J., et al. Effectiveness of platelet releasate for the treatment of diabetic neuropathic foot ulcers. Diabetes Care 24: 483, 2001.

22. Marx, R. E., Carlson, E. R., Eichstaedt, R. M., et al. Platelet-rich plasma: Growth factor enhancement for bone grafts. Oral Surg. Oral Med. Oral Pathol. Oral Radiol. Endod. 85: 638, 1998.

23. Petrungaro, P. S. Using platelet-rich plasma to accelerate soft tissue maturation in esthetic periodontal surgery. Compend. Contin. Educ. Dent. 22: 729, 2001

24. Robiony, M., Polini, F., Costa, F., et al. Osteogenesis distraction and platelet-rich plasma for bone restoration of the severely atrophic mandible: Preliminary results. J. Oral Maxillofac. Surg. 60: 630, 2002

25. Soffer, E., Ouhayoun, J. P., and Anagnostou, F. Fibrin sealants and platelet preparations in bone and periodontal healing. Oral Surg. Oral Med. Oral Pathol. Oral Radiol. Endod. 95: 521, 2003.

26. Welsh, W. J. Autologous platelet gel: Clinical function and usage in plastic surgery. Cosmetic Derm. 11: 13, 2000

27. Whitman, D. H., Berry, R. L., and Green, D. M. Platelet gel: An autologous alternative to fibrin glue with applications in oral and maxillofacial surgery. J. Oral Maxillofac. Surg. 55: 1294, 1997.

28. Shanaman, R., Filstein, M. R., and Danesh-Meyer, M. J. Localized ridge augmentation using GBR and platelet-rich plasma: Case reports. Int. J. Periodontics Restorative Dent. 21: 345, 2001

29. Eppley, B. L., Woodell, J. E., and Higgins, J. Platelet quantification and growth factor analysis from platelet-rich plasma: Implications for wound healing. Plast. Reconstr. Surg. 114: 1502, 2004. 
30. Kevy, S. V., and Jacobson, M. S. Comparison of methods for point of care preparation of autologous platelet gel. J. Extra Corpor. Technol. 36: 28, 2004

31. Marx, R. E. Platelet-rich plasma (PRP): What is PRP and what is not PRP? Implant Dent. 10: 225, 2001.

32. Waters, J. H., and Roberts, K. C. Database review of possible factors influencing point-of-care platelet gel manufacture. J. Extra Corpor. Technol. 36: 250, 2004.

33. Zimmermann, R., Arnold, D., Strasser, E., et al. Sample preparation technique and white cell content influence the detectable levels of growth factors in platelet concentrates. Vox Sang. 85: 283, 2003

34. Guyton, A. C. Physiology of the Human Body. Philadelphia: Saunders College Publishing, 1979.

35. Tischler, M. Platelet rich plasma: The use of autologous growth factors to enhance bone and soft tissue grafts. N. Y. State Dent. J. 68: 22, 2002

36. Conley, C. L. Hemostasis. In V. B. Mountcastle (Ed.), Medical Physiology. St. Louis: Mosby, 2004. Pp. 1137-1146

37. Caro, C. D., Pedley, T. J., Schroter, R. C., et al. The Mechanics of the Circulation. Oxford: Oxford University Press, 1978.

38. Harrison, P., and Cramer, E. M. Platelet alpha-granules. Blood Rev. 7: 52, 1993

39. Szpaderska, A. M., Egozi, E. I., Gamelli, R. L., et al. The effect of thrombocytopenia on dermal wound healing. J. Invest. Dermatol. 120: 1130, 2003

40. Lowe, H. C., Rafty, L. A., Collins, T., et al. Biology of platelet-derived growth factor. In E. Canalis (Ed.), Skeletal Growth Factors. Philadelphia: Lippincott Williams \& Wilkins, 2000. Pp. 129-151.

41. Woodward, S. C., and Salthouse, T. N. The tissue response to implants and its evaluation by light microscopy. In A. F. von Recum (Ed.), Handbook of Biomaterials Evaluation. New York:

Macmillan, 1986. Pp. 364-378

42. Frost, H. M. A 2003 update of bone physiology and Wolff's law for clinicians. Angle Orthod. 74: 3, 2004

43. Roseborough, I. E., Grevious, M. A., and Lee, R. C. Prevention and treatment of excessive dermal scarring. J. Natl. Med. Assoc. 96: 108, 2004

44. Weibrich, G., Kleis, W. K., Hafner, G., et al. Growth factor levels in platelet-rich plasma and correlations with donor age, sex, and platelet count. J. Craniomaxillofac. Surg. 30: 97, 2002. 
45. Lariviere, B., Rouleau, M., Picard, S., et al. Human plasma fibronectin potentiates the mitogenic activity of platelet-derived growth factor and complements its wound healing effects. Wound Repair Regen. 11: 79, 2003

46. Zhou, Y. Q., Levesque, J. P., Hatzfeld, A., et al. Fibrinogen potentiates the effect of interleukin-3 on early human hematopoietic progenitors. Blood 82: 800, 1993.

47. Sipe, J. B.Waits, C. A.Skikne, B. et al. The presence of bone morphogenetic proteins (BMPs) in megakaryocytes and platelets. Presented at the 24th Annual Meeting of the American Society for Bone and Mineral Research, San Antonio, Texas, September 20-24, 2002.

48. Gonshor, A. Technique for producing platelet-rich plasma and platelet concentrate: Background and process. Int. J. Periodontics Restorative Dent. 22: 547, 2002.

49. Mann, K. G. Thrombin formation. Chest 124 (3 Suppl.): 4S, 2003.

50. Weibrich, G., Kleis, W. K., Kunz-Kostomanolakis, M., et al. Correlation of platelet concentration in platelet-rich plasma to the extraction method, age, sex, and platelet count of the donor. Int. J. Oral Maxillofac. Implant. 16: 693, 2001.

51. Slater, M., Patava, J., Kingham, K., et al. Involvement of platelets in stimulating osteogenic activity. J. Orthop. Res. 13: 655, 1995

52. Arm, D. M. Autologous platelet-based therapies for orthopaedic tissue regeneration. Orthopedics 25: 169, 2002

53. Hannon, T. J., Polston, G., Pekarske, W. J., et al. Determination of Platelet Yields from Platelet Rich Plasma for Five Autotransfusion Devices. Cardiothoracic Research and Education Foundation, 1999.

54. Marlovits, S., Mousavi, M., Gabler, C., et al. A new simplified technique for producing platelet-rich plasma: A short technical note. Eur. Spine J. 13 (Suppl. 1): S102, 2004

55. Lozada, J. L., Caplanis, N., Proussaefs, P., et al. Platelet-rich plasma application in sinus graft surgery: Part I. Background and processing techniques. J. Oral Implantol. 27: 38, 2001

56. Hood, A. G., and Arm, D. M. Topical application of autogenous tissue growth factors for augmentation of structural bone graft fusion. Presented at the American Society of Extra-Corporeal Technology 11th Annual Symposium on New Advances in Blood Management, Las Vegas, Nev. April 20-23, 2004.

57. Arm, D. M. Characterization of an autologous platelet gel containing multiple growth factors. Transactions of the 45th Annual Meeting of the Orthopaedic Research Society, Anaheim, Calif., February 1-4, 1999

58. Weibrich, G., Kleis, W. K., and Hafner, G. Growth factor levels in the platelet-rich plasma produced by 2 different methods: Curasan-type PRP kit versus PCCS PRP system. Int. J. Oral Maxillofac. Implants 17: 184, 2002. 
59. Kevy, S. V., Jacobson, M. S., Blasetti, L., et al. Preparation of growth factor enriched autologous platelet gel (Paper no. 262). Transactions of the Society for Biomaterials 27th Annual Meeting, St. Paul, Minn., April 24-29, 2001.

60. Kevy, S. V., Jacobson, M. S., and Kadiyala, S. Characterization of growth factor levels in platelet concentrates. Presented at the 5th Annual Hilton Head Workshop on Engineering Tissues, Hilton Head, S.C., February $21-25,2001$

61. Anderson, N. A., Pamphilon, D. H., Tandy, N. J., et al. Comparison of platelet-rich plasma collection using the Haemonetics PCS and Baxter Autopheresis C. Vox Sang. 60: 155, 1991.

62. Christie, R. J., Carrington, L., and Alving, B. Postoperative bleeding induced by topical bovine thrombin: Report of two cases. Surgery 121: 708, 1997.

63. Rapaport, S. I., Zivelin, A., Minow, R. A., et al. Clinical significance of antibodies to bovine and human thrombin and factor V after surgical use of bovine thrombin. Am. J. Clin. Pathol. 97: 84, 1992.

64. Zehnder, J. L., and Leung, L. L. Development of antibodies to thrombin and factor $\mathrm{V}$ with recurrent bleeding in a patient exposed to topical bovine thrombin. Blood 76: 2011, 1990.

65. Knighton, D. R., Ciresi, K., Fiegel, V. D., et al. Stimulation of repair in chronic, nonhealing, cutaneous ulcers using platelet-derived wound healing formula. Surg. Gynecol. Obstet. 170: 56, 1990.

66. Ellis, D. A., and Shaikh, A. The ideal tissue adhesive in facial plastic and reconstructive surgery. J. Otolaryngol. 19: 68, 1990

67. Mandel, M. A. Minimal suture blepharoplasty: Closure of incisions with autologous fibrin glue. Aesthetic Plast. Surg. 16: 269, 1992

68. Powell, D. M., Chang, E., and Farrior, E. H. Recovery from deep-plane rhytidectomy following unilateral wound treatment with autologous platelet gel. Arch. Facial Plast. Surg. 3: 245, 2001.

69. Marchac, D., and Sandor, G. Facelifts and sprayed fibrin glue: An outcome analysis of 200 patients. Br. J. Plast. Surg. 47: 306, 1994

70. Oliver, D. W., Hamilton, S. A., Figle, A. A., Wood, S. H., and Lamberty, B. G. A prospective, randomized, double-blind trial of the use of fibrin sealant for facelifts. Plast. Reconstr. Surg. 108: 2102, 2001.

71. Fezza, J. P., Cartwrwight, M., Mack, W., and Flaharty, P. The sue of aerosolized fibrin glue in face-lift surgery. Plast. Reconstr. Surg. 110: 658, 2002

72. Marchac, D., and Greensmith, A. L. Early postoperative efficacy of fibrin glue in facelifts: A prospective randomized trial. Plast. Reconstr. Surg. 115: 911, 2005.

73. Jones, B. M., and Grover, R. Avoiding hematoma in cervicofacial rhytidectomy: A personal 8-year quest. Reviewing 910 patients. Plast. Reconstr. Surg. 113: 381, 2004. 
74. Marchac, D., Ascherman, J., and Arnaud, E. Fibrin glue fixation in forehead endoscopy: Evaluation of our experience in 206 cases. Plast. Reconstr. Surg. 100: 704, 1997.

75. Knighton, D. R., Fiegal, V. D., Doucette, M., et al. The use of topically applied platelet growth factors in chronic nonhealing wounds: A review. Wounds 1: 71, 1989.

76. Ganio, C., Tenewitz, F. E., Wilson, R., et al. The treatment of chronic nonhealing wounds using autologous platelet-derived growth factors. J. Foot Ankle Surg. 32: 263, 1993 